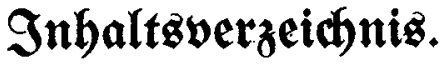

\author{
Seite \\ $\mathfrak{A} \mathfrak{b} \mathfrak{t} \mathfrak{u} \mathfrak{r} \mathfrak{z} \mathfrak{u} \mathfrak{n} \mathfrak{g} \mathfrak{e} \mathfrak{n} \ldots \ldots \ldots \ldots \ldots$ \\ Einleitung:

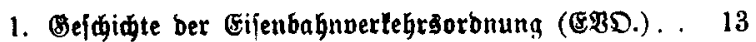 \\ 2. Die reftlife Bebeutung ber EפD. . . . . . 16 \\ 3. Die $\mathfrak{A}$ \&fuhrung\$beftinimungen . . . . . . . . 18 \\ 4. Die Dienftuoridiriften . . . . . . . . . . 19
}

\section{Clfenbabnbettebnorbutug (EQD.).}

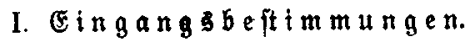

\$1. Beltungşbereid ... . . . . . . . . . 20

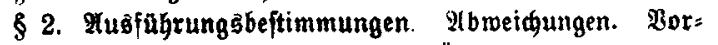

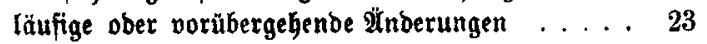

II. Allgemeine $\mathfrak{B}$ eft $i m u n g e n$.

§ 3. \$fligit zur Beip̈rderung . . . . . . . . 25

$\$$ 4. 3üge . . . . . . . . . . . . . 32

\$. \$aftung ber Eifenbahn für ihre seute...... 33

$\$ 6$. Tarife . . . . . . . . . . . . . 35

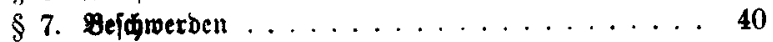

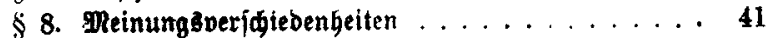

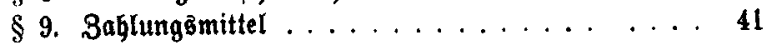


1II. Bejörderung oon ferionen 4

$\$ 10$. Jjahrplăne . . . . . . . . . . . . . 49

$\$ 11$. Bon ber Beförberung ausgejdlofjene ober nur bes bingungsimelje zugelajiene Perjonen . . . . . 5n

\$12. Jabrpreife. Ermäbigung für Rinber....... 52

$\$$ 13. Fabrlarten . . . . . . . . . . . . 911

$\$ 14$. Ebfung ber fagrlarten . . . . . . . . . . 96

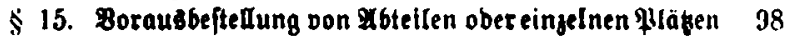

$\$ 16$. Frafung ber Fabrlarien. Fabrpreis̄jułંlăge. Babn: fteigfarten . . . . . . . . . . . . 104

$\S 17$. Marteräume . . . . . . . . . . . 111

$\$ 18$. Frauen= und Pidtrauderabteile . . . . . . 113

$\$ 19$. Einfteigen und Invelfung ber \$läbe ...... 114

$\$ 20$. Rúdnabme und umtaufid von fagrtarten . . . . 115

$\S$ 21. Xbfabrt. Berjäumnia ber 2bfajrt burd ben Meifenden ................ . 118

\$2:. Dffnen ber Fenfter . . . . . . . . . . . . 119

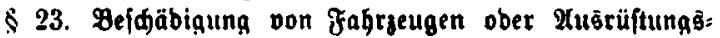
itüden. . . . . . . . . . . . . . . . 119

$\$$ 2t. Berfabrell auf 3rifdenjtationen. Fnbalten auf

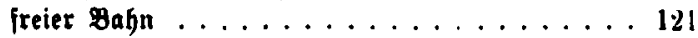

$\$ 25$. Unterbredung ber Fabrt auj Brolidenftationen. . 1:2

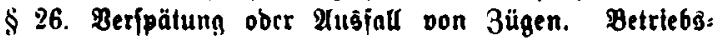
ftörungen. . . . . . . . . . . . . . 123

\$27. MRitnagme von Tieren in bie Plerjonenjüge ... 126

$\$ 28$. Dlitnahme von \$anbgepă in bie Perfonenwagen 129

$\$ 29$. Won ber Mlitnabme nusgeidlofiene Begenftănbe. . 133

IV. Beförberung oon Heifegepäd.

\$30. Degriff .................. 134

$\$ 31$. Berpadung Entfernung dlterer Beförberungä: zelden $\ldots \ldots \ldots \ldots \ldots \ldots \ldots \ldots$ 


\section{ingaltsoerjeidnis}

\$32. Xuftiejerung. Bepddijdein . . . . . . . . 141

\$33. 3olls ober ftetteramtlide, polizeilide Kbfertigung. 148

$\$$ 34. Fustieferung . . . . . . . . . . . . . 148

\$35. \$aftung ber Eijenbabn für Berluft, MRinberung ober Pejdabigung . . . . . . . . . 151

$\$$ 36. Berlujt don Feifegepäd . . . . . . . . . 153

$\$$ 37. \$aftung ber Eilenbahn für überidreitung ber \&ieferfrift. . . . . . . . . . . 15j

§ 38. Gepädträger ........ . . . . . . 156

\$39. थufbewahrung beş Bepäds . . . . . . . . 159

V. Beförberung oon Expésgut.

$\$ 40$ Unnabme......... . . . . . . 162

$\$$ 41. Beföberung . . . . . . . . . . . . 168

\$ 42. Eugliejerung. . . . . . . . . . . 169

\$43. \$eitere Boridriften . . . . . . . . . . 170

Vl. Beförberung von Leifen.

\$44. Xuflieferung $\ldots \ldots \ldots \ldots \ldots \ldots \ldots$

\$ 45. Beförberung . $\quad \ldots \ldots \ldots 178$

\$4. Eustieferung . . . . . . . . . . . . . . . 180

\$ 47. Xusnabmebeptimmungen $\ldots \ldots \ldots \ldots \ldots 181$

$\$$ 47a. Weltere Borídriften . . . . . . . . . 182

VII. Beforberung oan lebenden bieren.

$\$$ 48. Euflieferung $\ldots \ldots \ldots \ldots \ldots \ldots \ldots \ldots$

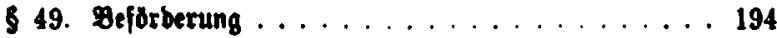

\$50. Yuslleferung . . . . . . . . . . . . . . 196

\$ 51. Qheferfrif .................. 198

\$52. \$eitere Boridriften . . . . . . . . . . 199 
VIII. beforberung oon (sitexn.

$\$ 5$ 3. Durdgehende Bejörberung . . . . . . . . . 202

$\$ 54$. Bon ber Beförderung ausgefdloffene oder- nur bebingungäveife jur Beförberung zugelaffene

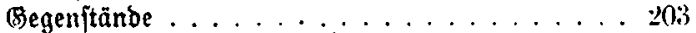

$\$ 5$ 5. Fradtbrief; feine form . . . . . . . . 212

$\$ 56$. Znhalt bes Fradtbriefes . . . . . . . . 216

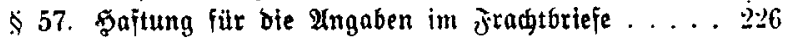

$\$ 58$ Yrüfung bes Snhalts ber Senbung. Feftftelfung

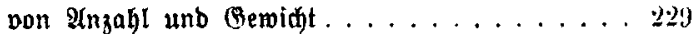

59. Relabung ber Wagen. Zabegervidt. Tragfähigfeit 234

$\$ 60$. Jrátgufdiäge . . . . . . . . . . . . 238

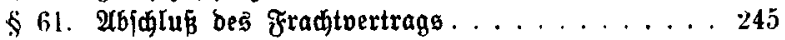

$\$$ 62. Betpadung und Bezeidgmung. . . . . . . . . . 249

$\$ 63$. \&tnnabme . . . . . . . . . . . . . . 259

$\$ 64$. Borläufige Einlagerung bes sute . . . . . . . 266

$\$ 65$. 3olf=, Steuer=, Wolizei= und ftatiftifde 3orfdriftet 269

\$66. Berwendung Gededter ober offerer $\mathfrak{M a g e n} . \ldots . .275$

\$ 67. 2rt und Reihenfolge ber Beförberung . . . . . . 276

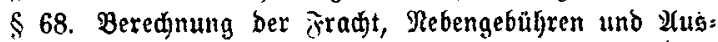
lagen . . . . . . . . . . . . . . 279

$\$ 69$. Bahlung ber fradjt . . . . . . . . . . 282

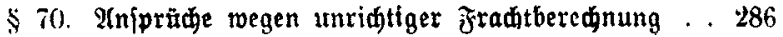

71. Yeriährung ber :Hnprethe megen unridtiget Fradt: beredinting . . . . . . . . . . . . . 290

72. Radnabme nad Eingang. Barvoriduई . . . . 291

§ 73. Radträglidje Berfügungen besె Ab\{enders . . . . 295

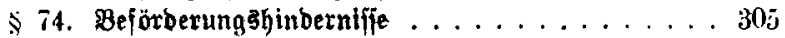

$\$ 75$. Sieferfrift. . . . . . . . . . . . . 307

$\$ 76$. 2tblieferung . . . . . . . . . . . . . 312

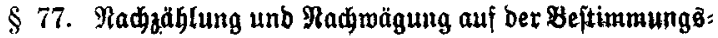
itation . . . . . . . . . . . . 322 
\$ $78.3 u$ fügrung $\ldots \ldots \ldots \ldots \ldots \ldots \ldots$

\$ 79. Benadridgtigung des Empfängerś non ber 2 Infunit . 326

$\S 80$. Friften für die Abnahme ber niđut zugerollten Gütcr. . . . . . . . . . . . . . . . 329

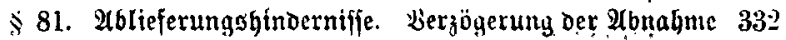

\$ 8:. Feftftellung von Minderung, Yejdäbigung ober Berluft bes (Futes burd bie Eijenbagn . . . . . 339

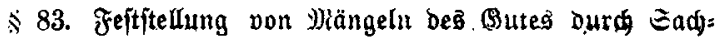
verítänbige ober burdy bas (Pexidgt . . . . . . 343

$\$ 84$. Faftung ber Eifenbahn für $\mathfrak{W e r l u j t , ~}$ Rinderung ober Bejđäbigung beş Butes̃ int allgemeinen . . . . . 344

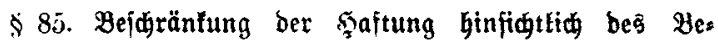
ftimmungsoortes . . . . . . . . . . . 349

$\$ 86$. Bejdränfung Der şattung bei befonoeren (Befahren 350

\$87. Beidräntung ber \$̧aftung bei (Hewidgtâverluften . 363

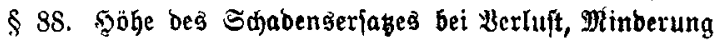
ober Befódäbigung bes butes . . . . . . . . 365

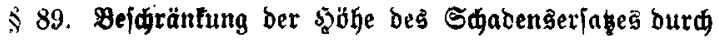
ben Tarif . . . . . . . . . . . . . 369

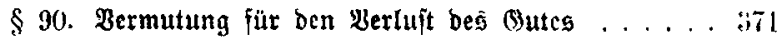

\$ 91. Miederauffinden bes (sutes . . . . . . . . 371

\$ 92. Ungabe des 3ntereffes an ber ziejerut!. . . . . 373

§ 93.. \$öbe bę Sqabengెerjałes̆ für Berluft, Minderung ober Befđäbigung bei $\mathfrak{2}$ ngabe bes Jntereffes an ber Rieferung ................ 375

$\$ 94$. Saftung für itberidreitung Der viejerfrift $\ldots \ldots 375$

$\$$ 95. Gdabengerfas bet Borja ober grober Fabrläffitgfeit der Etienbabn . . . . . . . . . . . . 379

\$ 96. Berwirtung ber Erfaganfprüde . . . . . . . . . 382

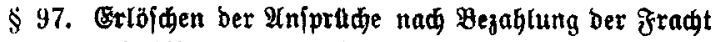
unb 2 (bnahme des guteg . . . . . . . . 383 
\$98. Berjägrung ber 2unjprüфe gegen bie Elfenbabn megen Rerlujtes, Minberung ober Belgäblgung bes Butes ober wegen itberforeitung ber Rieferfrift. . 387

$\$ 99$. Deltenbmadung ber Medte aus bent fradivertrag. 390

$\$ 100$ saftung megrerer an ber seförberung beteifigter Eljenbagnen . . . . . . . . . . . 393

Inlage B วu $\$ 49$ (2) EBD : Rähere Beftimmungen über ble Peförberung von Iebenden gieren . . . . . 396

$\$ 898.453-473 \ldots \ldots \ldots \ldots \ldots \ldots \ldots$ 340. . . . . . . . . . . . . . . . . . . 409 $\mathbf{3} \mathfrak{u} \mathbf{p} \ldots \ldots \ldots \ldots \ldots \ldots \ldots$

Sadregifter ................ 